\title{
Redevelopment of ADVISOR for Design and Simulation of Plug-in Hybrid Electric Vehicle
}

\author{
Gang Chen \\ ${ }^{1}$ School of Mechanical \& Electronic \\ Eng., \\ Sanming Univ., \\ Sanming, 365004, China
}

\author{
Long $\mathrm{Wu}^{2}$ \\ ${ }^{2}$ Sanming Engineering Research \\ Center of Mechanical CAD, \\ Sanming, 365004, China
}

\author{
Lei $\mathrm{Wu}^{3}$ \\ ${ }^{3}$ School of Mechanical \& Electronic \\ Eng., \\ Sanming Univ., \\ Sanming, 365004, China
}

\begin{abstract}
The rear drive hybrid electric vehicle system and control model are established based on the dynamics equation and redevelopment of ADVISOR. After importing the Chinese city bus typical condition in ADVISOR, the power performance and fuel economy of the vehicle are simulated and analyzed. The simulation results show that the hybrid electric vehicle compared with the prototype vehicle has a great improvement on fuel economy, and its power performance can meet the design requirements. The hybrid electric vehicle simulation system has very good feasibility that can provide technical support for the development of experimental prototype, and contribute to shorten the development period and reduce costs.
\end{abstract}

Keywords-ADVISOR redevelopment; hybrid electric vehicle; modeling; simulation.

\section{INTRODUCTION}

The Ministry of Environmental Protection recently released "2013 Chinese motor vehicle pollution and controlling annual report" that shows vehicle emission has become a major source of air pollution[1]. The widespread use of Hybrid Electric Vehicle (HEV) and Electric Vehicle (EV) is one of the effective methods for the improvement or resolution of automobile exhaust pollution. Computer simulation is an important way to study HEV and EV, which greatly contributes to shorten the development period and reduce development costs[2]. At present, the domestic and foreign researchers study HEV by using computer simulation software such as CRUISE, CarSim, PSAT and ADVISOR[3]. ADVISOR is working in the MATLAB/SIMULINK environment with modular programming language. ADVISOR has a good advantage that its code is completely open and free. The users can easily master and redevelop ADVISOR by its open code [4, 5]. ADVISOR was developed by the National Renewable Energy Laboratory of America. There is hybrid simulation method in ADVISOR that mainly uses backward simulation and combines with forward simulation. We can use ADVISOR to realize the vehicle assembly parameters matching and optimization, simulate and analyze the HEV dynamic and economic performance, and evaluate the rationality of energy management strategy[6]. However, ADVISOR also has its own defects. For example its simulation models are limited and it is only suitable for the simulation of the single axis front drive vehicle. Thus, this paper redevelops ADVISOR for a rear drive hybrid electric city bus. By taking MATLAB/SIMULINK as the platform and using the open code and internal generic modules, the simulation models are established and carried on the simulation and analysis in the paper, which provides a strong technical basis for the design of HEV.

\section{REDEVELOP ADVISOR FOR HEV SIMULATION SYSTEM}

\section{A. The structure and working principle of the HEV}

The HEV in the paper is a rear drive city bus with parallel structure driveline. The power system using ISG motor, ISG motor is a starting and generating integrated machine which is widely used in HEV now. The power system can realize multiple operating modes, such as: (1) when the vehicle is starting or at low speed operating, and the SOC value is greater than the low limit value, the engine is shut down and the battery supplies power to ISG motor to drive vehicle; (2) when the vehicle is at high-speed operating, the battery group stop working and engine drives vehicle alone; (3) when the demand power is greater than the engine can provide, engine and battery work together to provide torque to drive vehicle[7]; (4) when vehicle is at idle speed, braking or downhill, the mechanical energy from engine begins to generate electricity that be stored in battery group by ISG motor.

\section{B. Redevelop the simulation system of $\mathrm{HEV}$}

The hybrid system in the paper is rear drive form and the simulation models of the original in ADVISOR software is only for front drive. There are great differences. In order to achieve the research purpose, it is necessary to redevelop ADVISOR simulation modules.

The establishing idea of front drive simulation models in ADVISOR is first to establish and solve the dynamics equation of the vehicle on slope road, and then create the SIMULINK models based on the dynamics equation. The following is the force analysis of the rear wheel drive vehicle on slope road, as shown in Figure 2. Assuming that the vehicle is limit attachment, the initial velocity is $V_{0}$, and the maximum terminal velocity under the maximum 
adhesion $F_{\max }$ is $V_{\mathrm{t}}$. Among them, $F_{\mathrm{W}} 、 F_{\mathrm{f}} 、 F_{\mathrm{i}}$ respectively are the air resistance, rolling resistance and slope resistance. $F_{\mathrm{n}}$ is the vertical load on the driving wheel.

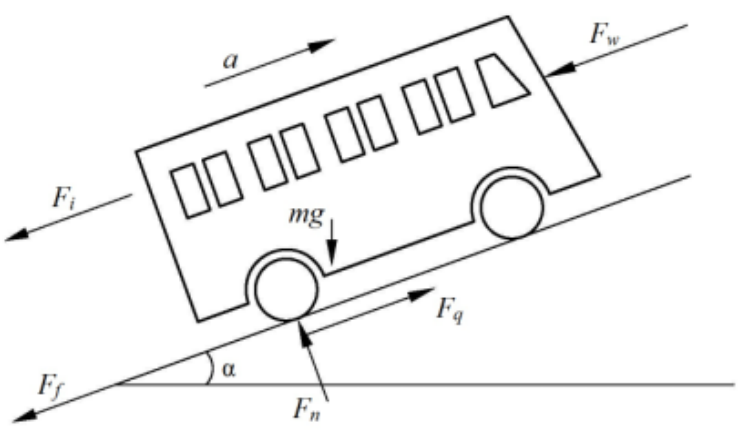

Figure 1. Force analysis of rear drive vehicle on slope road

According to force balance of the vehicle, there is:

$$
F_{\text {max }}-F_{w}-F_{f}-F_{i}=m a
$$

Among them,

$$
\begin{aligned}
F_{\max }=F_{\mathrm{q}}= & F_{n} * \varphi \\
V_{\mathrm{t}}= & {\left[\varphi m g \cos \alpha \cdot b / l-m g\left(f_{1} \cos \alpha+\sin \alpha\right)-m g \cos \alpha \cdot f_{2} V_{0} / 2-\right.} \\
& \left.\sigma C_{d} A V_{0}^{2} / 8-\varphi \frac{m V_{0}}{d t} \frac{h_{g}}{l}+\varphi m g \frac{h_{g}}{l} \sin \alpha+m V_{0} / d t\right] /\left[\frac{3}{8} \sigma C_{d} A V_{0}\right. \\
& \left.+\frac{1}{2} m g f_{2} \cos \alpha+m / d t+\varphi \frac{h_{g}}{l} m / d t\right] \\
V_{\mathrm{t}}^{\prime}= & {\left[-\varphi m g \cos \alpha \cdot b / l-m g\left(f_{1} \cos \alpha+\sin \alpha\right)-m g \cos \alpha \cdot f_{2} V_{0} / 2-\right.} \\
& \left.\sigma C_{d} A V_{0}{ }^{2} / 8+\varphi \frac{m V_{0}}{d t} \frac{h_{g}}{l}-\varphi m g \frac{h_{g}}{l} \sin \alpha+m V_{0} / d t\right] /\left[\frac{3}{8} \sigma C_{d} A V_{0}\right. \\
& \left.+\frac{1}{2} m g f_{2} \cos \alpha+m / d t+\varphi \frac{h_{g}}{l} m / d t\right]
\end{aligned}
$$

In order to make demand traction force cannot exceed the maximum traction force that the wheel can provide and rear wheel drive vehicle's simulation speed do not exceed the actual operation ability when the vehicle is in the limit adhesion[8], it should limit the tire maximum speed, driving and braking forces in ADVISOR according to the above dynamics equations. And the front drive modules are modified, replaced and repackaged. Then traction force control system and the whole rear drive vehicle model are built up eventually as following. 


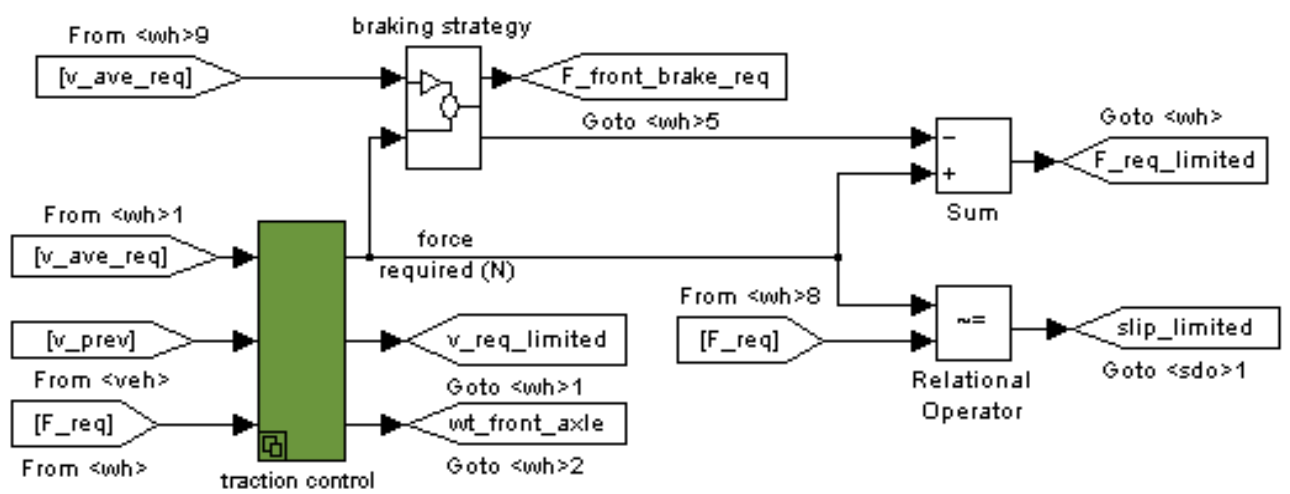

Figure 2. Traction force control model

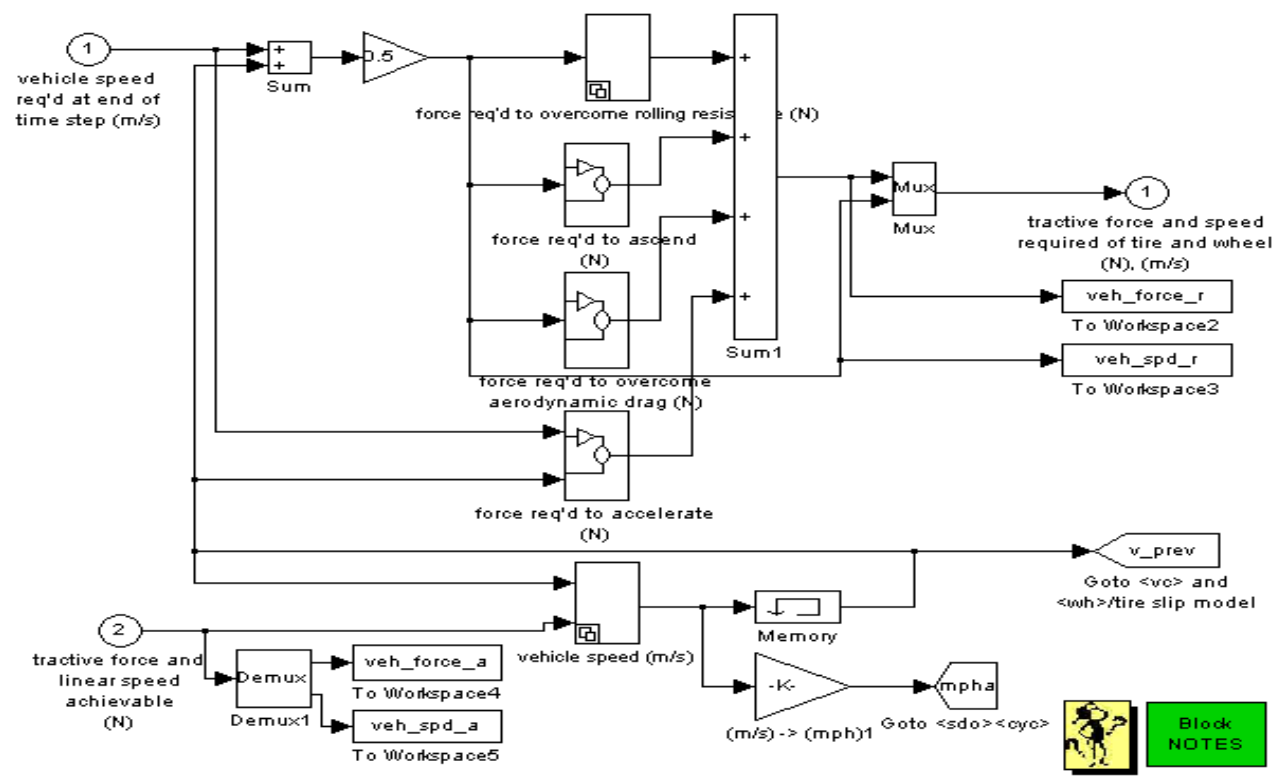

Figure 3. Simulation model of rear drive vehicle

\section{Control strategy model design of the hybrid system}

Parts of models in ADVISOR that are steady models were established by experience data, which usually lead to the simulation result not satisfied. And there are some difference between the control strategy in the paper and ADVISOR's. Therefore, it is essential to redesign the control strategy. Because vehicle itself is a nonlinear system, if it uses traditional PID control it must transform the nonlinear system to linear. It will cost lots of time. Considering these factors, the fuzzy logic control strategy was used in the parallel hybrid electric vehicle in this paper. Acording to the relationship between pedal open angle, vehicle speed and SOC, the power distribution of fuzzy logic module makes the engine and motor keep the best power allocation. Figure 4 is the basic structure of fuzzy power controller.

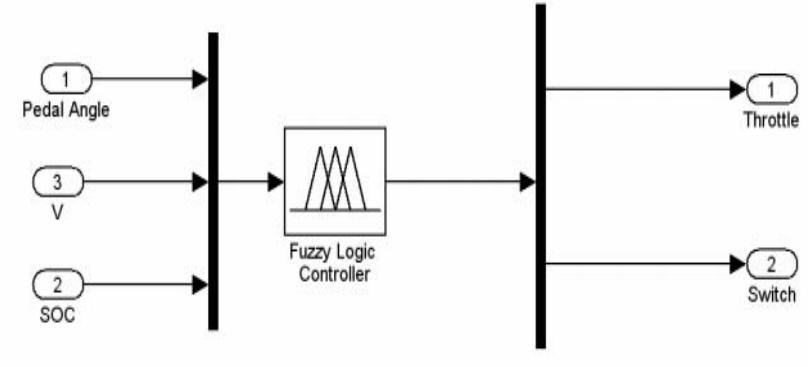

Figure 4 . The basic structure of fuzzy power controller

The control algorithm of the hybrid system control strategy is shown in Figure 5. The whole demand power is obtained by driver's action to the accelerator or brake pedal; the controller decides the energy flow of hybrid system according to the demand power; then the running state of engine and motor is determined by SOC according to vehicle speed, load and SOC value. Therefore, the $\langle\mathrm{vc}\rangle$ submodule of engine_on module is modified and the 
control strategy is defined as following figure $6: \mathrm{V}<$ $30 \mathrm{~km} / \mathrm{h}, \mathrm{SOC}>0.3$, the engine is off and motor is on; $\mathrm{V}>$ $30 \mathrm{~km} / \mathrm{h}, \mathrm{SOC}>0.3$, engine and motor work together; SOC $<0.3$, the motor is off and battery groups begin to be charged.

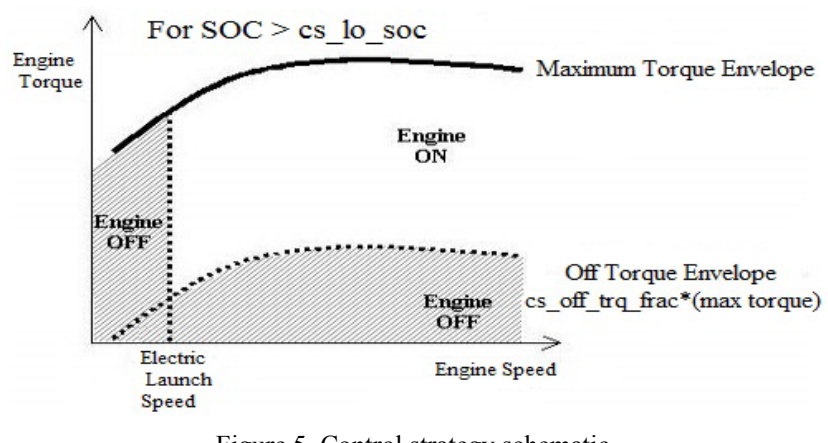

Figure 5. Control strategy schematic

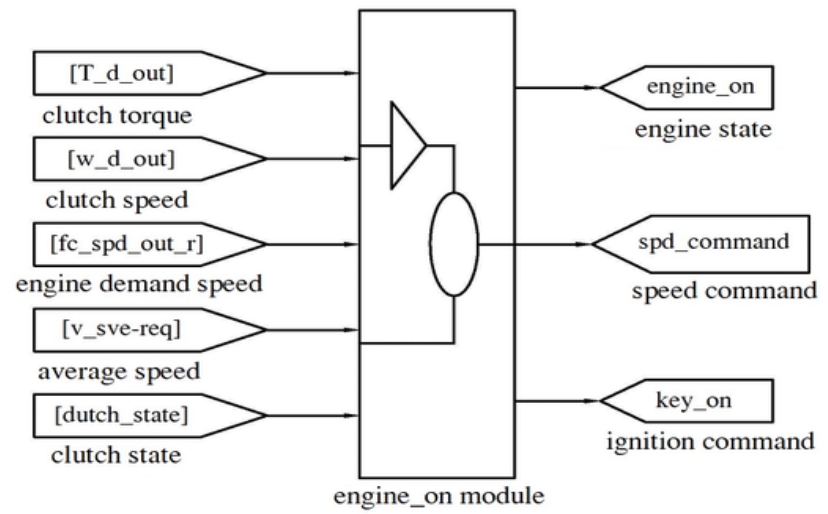

Figure 6. Engine switch control module

\section{SIMULATION AND RESULTS ANALYSIS}

It can obtain different result when different road driving cycle is selected in ADVISOR simulation, so it is very important to select suitable road driving cycle. In order to make the simulation more closer to the practical condition, Chinese typical city bus driving cycle was imported into ADVISOR and this driving cycle was selected to simulate and analyze economic performance in the paper. Figure 7 indicates Chinese typical city bus driving cycle that is shown as following. Because its simulation upper limit speed is $60 \mathrm{~km} / \mathrm{h}$, then USA EPA city driving cycle CYC-UDDS was selected to simulate the maximum speed.

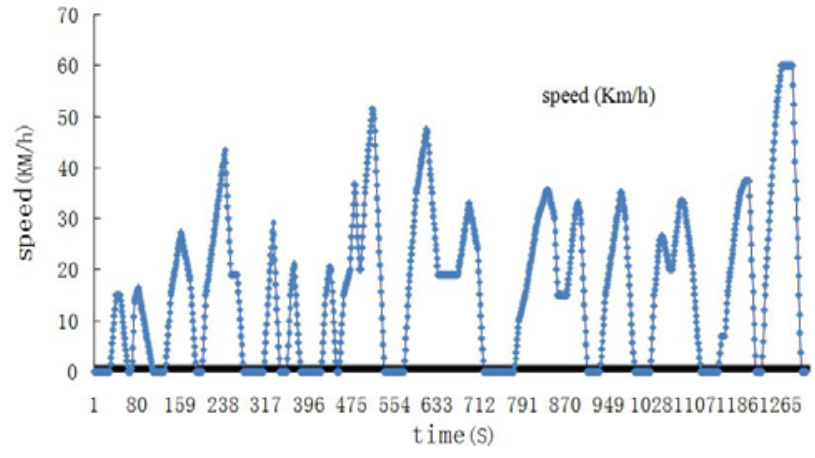

Figure 7. Chinese typical city bus driving cycle

The rear drive hybrid system and control models that were established in the paper were integrated to simulate the fuel economy and dynamic performance with Chinese typical city bus driving cycle and CYC-UDDS driving cycle in ADVISOR. Basic parameter of the prototype vehicle is shown in table I. Table II and table III are the fuel economy and dynamic performance simulation results. Because the speed in Chinese typical city bus driving cycle is very low in most of time and the average speed is only $16.1 \mathrm{~km} / \mathrm{h}$; the speed changes frequently, so the fuel economic performance of the $\mathrm{HEV}$ is improved significantly.

TABLE I. BASIC PARAMETER OF THE PROTOTYPE VEHICLE

\begin{tabular}{cccc}
\hline $\begin{array}{c}\text { Vehicle curb } \\
\text { mass }(\mathrm{kg})\end{array}$ & 10000 & $\begin{array}{c}\text { Rolling resistance } \\
\text { coefficient }\end{array}$ & 0.01 \\
\hline $\begin{array}{c}\text { Loading } \\
\text { weight }(\mathrm{kg})\end{array}$ & 4500 & $\begin{array}{c}\text { Transmission } \\
\text { efficiency }\end{array}$ & 0.85 \\
\hline $\begin{array}{c}\text { Air resistance } \\
\text { coefficient }\end{array}$ & 0.65 & $\begin{array}{c}\text { mass center } \\
\text { height }(\mathrm{m})\end{array}$ & 0.7 \\
\hline $\begin{array}{c}\text { Windward } \\
\text { area(m2) }\end{array}$ & 7.4 & Wheel base(m) & 5.6 \\
\hline $\begin{array}{c}\text { Wheel rolling } \\
\text { radius(m) }\end{array}$ & 0.5 & & \\
\hline
\end{tabular}

TABLE II. FUEL ECONOMY PERFORMANCE SIMULATION RESULT

\begin{tabular}{|c|c|c|}
\hline prototype vehicle & $\begin{array}{c}\text { driving cycle } \\
\text { chinese typical } \\
\text { bus driving } \\
\text { cycle }\end{array}$ & $\begin{array}{c}\text { equivalent fuel } \\
\text { consumption } \\
\text { /L.(100km)-1 }\end{array}$ \\
\hline HEV & $\begin{array}{c}\text { Chinese typical } \\
\text { city } \\
\text { bus driving } \\
\text { cycle }\end{array}$ & 38.6 \\
\hline
\end{tabular}

TABLE III. DYNAMIC PERFORMANCE SIMULATION RESULT

\begin{tabular}{clc}
\hline Simulation project & driving cycle & value \\
\hline maximum speed $(\mathrm{km} / \mathrm{h})$ & CYC-UDDS & 90.5 \\
\hline $\begin{array}{c}0-50 \mathrm{~km} / \mathrm{h} \text { accelerating } \\
\text { time }(\mathrm{s})\end{array}$ & CYC-UDDS & 14.8 \\
\hline $\begin{array}{c}16 \mathrm{~km} / \mathrm{h} \text { climbing } \\
\text { gradient }(\%)\end{array}$ & CYC-UDDS & 21.5 \\
\hline
\end{tabular}


Figure 8 is the speed simulation result curve in CYC-UDDS driving cycle. From the curve, we can read that the maximum simulation speed is $90.5 \mathrm{~km} / \mathrm{h}$ and the simulation results of acceleration and climbing performance also meet the design target. Through the output check plots in ADVISOR' result output interface, the working diagrams of dynamic units can obtain. Figure 9 and 10 are dynamic transmission system simulation efficiency and motor simulation efficiency map. From the output map, it is obvious that most work efficiency points of motor are in 0.8 above. Therefore, the simulation results are ideal.

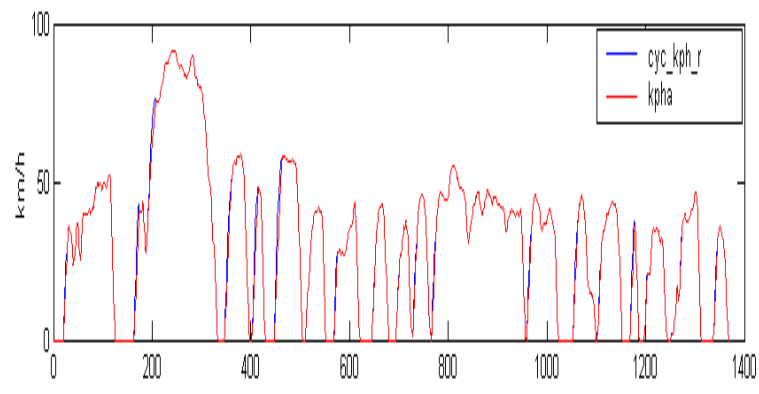

Figure 8 . The speed simulation result

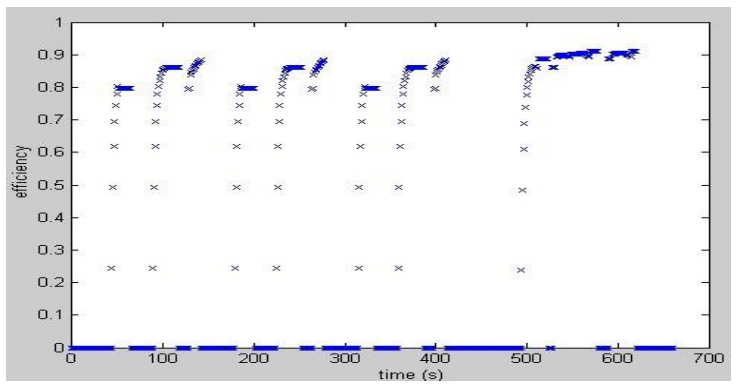

Figure 9. Motor simulation efficiency

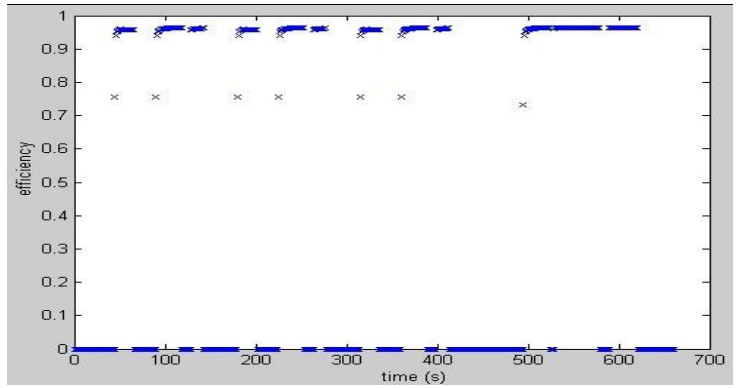

Figure 10. Transmission system simulation efficiency

\section{CONCLUSIONS}

The paper makes full use of the open code of ADVISOR and redevelops the rear drive model and control system model of the hybrid electric city bus on the basis of existing simulation models in ADVISOR. And Chinese typical city bus driving cycle is imported into ADVISOR successfully, which makes the simulation more closer to actual situation. The simulation results show that, the dynamic system and control strategy established in the paper can simulate the power and fuel economy performance of the HEV very well. Compared with the prototype vehicle, the fuel economy performance of HEV is improved obviously, and its power performance also meet the design requirements. The simulation provides great technique support for the HEV being put into production and reduces lots of development time and research cost for the company.

\section{ACKNOWLEDGEMENTS}

This work was supported and funded by the project (JK2013050) from the Science and Technology Foundation of the Education Department of Fujian Province.

\section{REFERENCES}

[1] Ministry of Environmental Protection, 2013 Chinese motor vehicle pollution and controlling annual report, http://www.mep.gov.cn/gkml/hbb/qt/201401/t20140126 266973.htm, 2014.

[2] Xu, B. Y., and Wang, W. R., Computer modeling and simulation technology, Beijing: Beijing Institute of Technology Press, 1-15, 2009

[3] Zhang, X. and Qian, L. J., Development of electric vehicle simulation software, Journal of system simulation, Vol.16, 1621-1623, 2004.

[4] National Renewable Energy Laboratory, ADVISOR2002 Help Document, http://www.ctts nrel gov/analysis, 2002.

[5] Zeng, X. H., and Wang, Q. N., Development of Forward and Simulation Model in ADVISOR 2002, Journal of automotive engineering, Vol.29, 851-854, 2007.

[6] Markel T, Brooker A, Hendricks T, et al., ADVISOR: A systems analysis tool for advanced vehicle modeling, Journal of Power Sources, Vol.110, 255-266, 2002.

[7] Yu, Z. S., Automobile theory, Beijing: China Machine Press, 57-66, 2006.

[8] Zeng, X. H., and Gong, W. J., Simulation and redevelopment of electric vehicle based on ADVISOR 2002, Beijing: China Machine Press, 213-233, 2014. 